Portland State University

PDXScholar

$11-1-2004$

\title{
Patterns of Fitness and Fluctuating Asymmetry Across a Broad Hybrid Zone
}

Mitchell B. Cruzan

Portland State University

Follow this and additional works at: https://pdxscholar.library.pdx.edu/bio_fac

Part of the Biology Commons, and the Plant Breeding and Genetics Commons

Let us know how access to this document benefits you.

\section{Citation Details}

Handy, S. M., McBreen, K., and Cruzan, M. B. (2004). Patterns of Fitness and Fluctuating Asymmetry Across a Broad Hybrid Zone. International Journal of Plant Sciences, 165(6), 973-981.

This Article is brought to you for free and open access. It has been accepted for inclusion in Biology Faculty Publications and Presentations by an authorized administrator of PDXScholar. Please contact us if we can make this document more accessible: pdxscholar@pdx.edu. 
Int. J. Plant Sci. 165(6):973-981. 2004.

(c) 2004 by The University of Chicago. All rights reserved.

1058-5893/2004/16506-0006\$15.00

\title{
PATTERNS OF FITNESS AND FLUCTUATING ASYMMETRY ACROSS A BROAD HYBRID ZONE
}

\author{
Sara M. Handy, ${ }^{1}$ Kim McBreen, ${ }^{2}$ and Mitchell B. Cruzan ${ }^{3}$ \\ Department of Biology, Portland State University, Portland, Oregon 97207, U.S.A.
}

\begin{abstract}
We estimated levels of developmental instability in leaves, as indicated by fluctuating asymmetry (i.e., random deviations from perfect bilateral symmetry), across a broad hybrid zone between two taxa in the Piriqueta caroliniana complex. Previous studies have indicated that this hybrid zone was initiated in southern Florida and has expanded northward. We found that plants from the hybrid zone generally had higher levels of leaf developmental instability than plants from allopatric regions, but the increase in asymmetry was not substantial. Although it is usually assumed that developmental instability is associated with lower fitness, these Piriqueta hybrids from central Florida are similar in fitness (estimated by vegetative growth, survival, and reproduction over three growing seasons) to plants from the allopatric regions, and levels of asymmetry were not correlated with fitness for population averages or individuals. We interpret these patterns as evidence that mildly deleterious genetic incompatibilities, which contribute to developmental instability, may have been fixed in hybrid populations as a result of genetic drift.
\end{abstract}

Keywords: developmental stability, fitness, genetic incompatibility, introgression, recombinant hybrids.

\section{Introduction}

Developmental stability has been defined as the ability of an individual to form the optimal phenotype, which is often interpreted as perfect symmetry in a bilaterally structured organism (Mather 1953; Thoday 1955; Waddington 1957; Palmer and Strobeck 1986; Møller and Swaddle 1997; Nijhout and Davidowitz 2003). Organisms may exhibit different kinds of asymmetry, including directional asymmetry (one side of a bilateral structure or organism is consistently larger than the other) and antisymmetry (sides are consistently unequal in size, but neither side is more likely to be the largest). Weak developmental homeostasis may be evident as random departures from perfect symmetry, or fluctuating asymmetry (Graham et al. 1993). For organisms or structures that are normally symmetrical, fluctuating asymmetry (FA) has become a useful tool in measuring developmental stability because the optimal phenotype can be easily defined (Møller and Shykoff 1999; Nijhout and Davidowitz 2003). Of the three types of asymmetry, FA (Van Valen 1962; Palmer and Strobeck 1986; Parsons 1990; Møller and Swaddle 1997) and, under particular circumstances, directional asymmetry (Graham et al. 1998, 2003) are typically thought to be indicative of developmental instability.

\footnotetext{
${ }^{1}$ Current address: The Graduate College of Marine Studies, Hugh R. Sharp Campus, University of Delaware, Lewes, Delaware 19958, U.S.A.

2 Current address: Allan Wilson Center for Molecular Ecology and Evolution, Institute of Molecular BioSciences, Massey University, Private Bag 11222, Palmerston North, New Zealand.

${ }^{3}$ Author for correspondence; e-mail cruzan@pdx.edu.

Manuscript received February 2004; revised manuscript received May 2004.
}

Random departures from symmetrical morphology have been attributed to a number of causes. For example, Leary and Allendorf (1989) suggest that environmental stress may reduce the amount of resources spent on developmental checks, leading to differences in the growth of the matching sides of bilateral structures. Palmer and Strobeck (1986) emphasized genetic influences on an individual's symmetry and suggested that both the level of heterozygosity (e.g., increased FA from inbreeding) at individual loci and interactions among loci (e.g., increased FA in hybrids) were important. In hybrid populations, these within-locus and among-loci effects may act simultaneously (Hochwender and Fritz 1999; Siikamaki 1999). For example, the effect of increased heterozygosity on stability may be counterbalanced by negative epistasis, or the breakup of coadapted gene complexes in recombinant genotypes (Graham 1992; Clark 1993). Under some circumstances, the effects of genetic stress may be obscured by environmental variation; therefore, care should be taken when interpreting patterns of FA observed in the field (Graham 1992; Hochwender and Fritz 1999). Although there has been much research on patterns of FA in animals, there is increasing interest in its value for studies of environmental and genetic stress in plants (Møller and Shykoff 1999; Tracy et al. 2003).

The relative fitness of hybrids and their parental taxa has been widely debated (Arnold and Hodges 1995; Graham et al. 1995; Arnold 1997; Barton 2001; Lexer et al. 2003). Because reduced developmental stability is generally assumed to be symptomatic of low fitness (Van Valen 1962; Parsons 1990; Møller and Swaddle 1997), FA has been used as an indicator of hybrid breakdown in recombinant genotypes (Graham 1992; Freeman et al. 1995; Hochwender and Fritz 1999; but see Andalo et al. 2000). Plants make excellent model systems for the study of FA in hybrids because (1) 
hybridization is relatively common in plants, (2) the sedentary nature of plants facilitates the control of environmental influences on levels of FA, and (3) asymmetry is easily quantified because many morphological features of plants (e.g., the midrib of dicot leaves) define landmarks that facilitate the measurement of the sides of bilateral organs. In this article, we examine patterns of FA in the parental and hybrid genotypes of the Piriqueta caroliniana complex (Ornduff 1970). This system is of particular interest for the study of FA because populations in different portions of the hybrid zone in central Florida appear to have different histories and vary in the time since initial hybridization (Martin and Cruzan 1999; Maskas and Cruzan 2000).

The $P$. caroliniana (=Piriqueta cistoides ssp. caroliniana, Turneraceae; as defined by Arbo 1995) complex is a group of perennial herbs that are widespread throughout South America, the Caribbean, and southeastern North America. In Florida and Georgia, the complex consists of at least four different morphotypes (Maskas and Cruzan 2000), and two of these, viridis $(\mathrm{V})$ and caroliniana $(\mathrm{C})$, hybridize and form a broad hybrid zone across the Florida peninsula (Martin and Cruzan 1999). A suite of morphological and diagnostic genetic characters distinguishes these two morphotypes from each other, and phenotypic differences are maintained under greenhouse conditions (Martin and Cruzan 1999; Maskas and Cruzan 2000). However, they have similar flowering morphology and can be crossed to produce viable hybrids (Gavrilets and Cruzan 1998; Wang and Cruzan 1998).

The hybrid zone in central Florida appears to have expanded northward over the past 5000-7000 yr (Martin and Cruzan 1999; Maskas and Cruzan 2000). For this study, we divided the distributions of these morphotypes and their hybrids into five regions on the basis of the position of clines and inferred patterns of gene flow (M. B. Cruzan, unpublished data). Allopatric populations of the $\mathrm{V}$ morphotype are restricted to the southern part of Florida (region 5), and allopatric populations of $\mathrm{C}$ are present in the Florida panhandle and southern Georgia (region 1; fig. 1). Allopatric populations appear to be largely isolated from introgression, on the basis of diagnostic morphological and genetic marker data (Martin and Cruzan 1999). Hybrid genotypes occupy a broad region across most of the Florida peninsula that we divided into three regions: the southern portion of the hybrid zone (region 4), the central hybrid zone (region 3), and the northern portion of the hybrid zone (region 2). The southernmost extent of the hybrid zone (region 4 ) has been subject to recent introgression from allopatric V populations (M. B. Cruzan, unpublished data); therefore, hybrids in this region would be expected to be a mixture of younger and advancedgeneration hybrids. Patterns of gene flow indicate that the populations in the central portion of the hybrid zone (region 3) contain primarily advanced-generation hybrids, while the

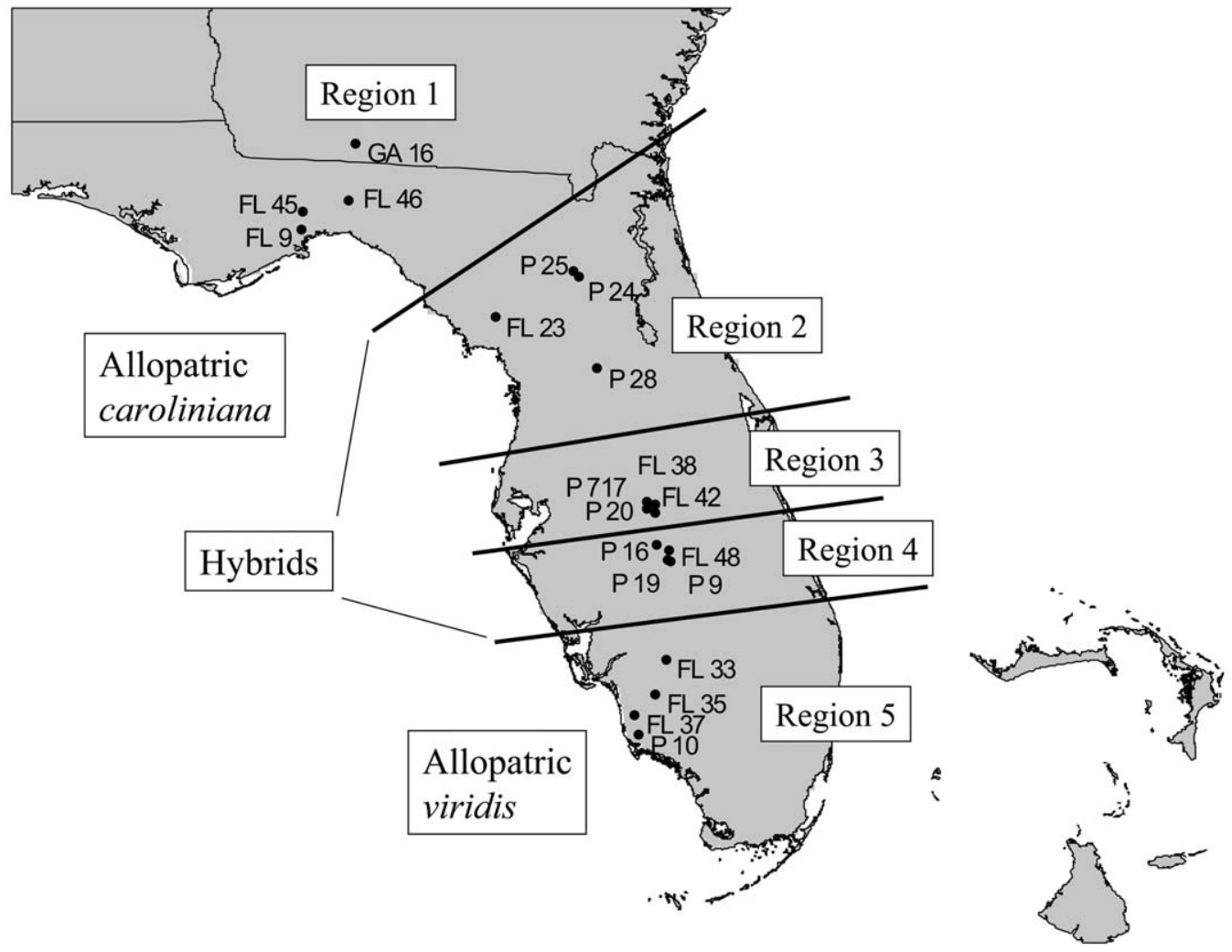

Fig. 1 Distribution of the field population sites for studies of fluctuating asymmetry in Piriqueta caroliniana. The distribution was divided into five regions for analysis as follows: region 1, allopatric C; region 2, northern hybrid zone (most recent area of hybrid zone expansion); region 3, central hybrid zone (older hybrid populations); region 4, southern hybrid zone (recent introgression from the south); and region 5, allopatric V. 
northern region, where the hybrid zone has more recently expanded into areas previously occupied by the $\mathrm{C}$ morphotype (region 2), should contain a higher proportion of earlygeneration hybrids (Martin and Cruzan 1999; M. B. Cruzan, unpublished data). These patterns of introgression and hybrid zone expansion, and the substantial amount of information available on the performance of these plants under field conditions (Cruzan and Rhode 2004; M. B. Cruzan, unpublished data), provide an ideal system for studying the effect of hybridization on patterns of developmental stability and the association between levels of asymmetry and fitness.

In this article, we examine patterns of developmental stability inferred from the level of FA of leaves in parental and hybrid genotypes across the Piriqueta hybrid zone in central Florida. In particular, we wished to determine whether the level of FA was greater in hybrid than in parental genotypes and whether increased FA was indicative of lower fitness. Within the hybrid zone, we expected that if developmental instability were due to genetic stress, hybrid populations that had experienced introgression more recently would display higher levels of FA than older hybrid populations. To control for environmental variation, we sampled hybrid and parental genotypes from the same populations grown under greenhouse and field conditions. Our results indicate that hybrids display less developmental stability than plants from allopatric regions; however, the increase in FA in hybrids was not substantial and was not associated with reduced fitness.

\section{Material and Methods}

\section{Leaf Collections and Measurements}

Leaf samples were obtained from plants in natural populations and from greenhouse plants grown from field-collected seeds. Leaves from field plants were sampled from four populations in each of five different regions across Florida from the panhandle and neighboring regions of Georgia to southern Florida near Naples (fig. 1). The habitats of field collection sites varied from deep sandy soils and turkey oak scrub in northern and central Florida to periodically flooded slash pine flatwoods in the south.

Between 10 and 20 individuals $($ mean $=18.1)$ were sampled from each population in the field, and leaves were collected from as many representatives of each population as were available in the greenhouse $(n=2-10$; mean $=6.2)$. If more than 20 individuals were present in natural populations, plants were sampled haphazardly, although care was taken to collect plants that were at least $1 \mathrm{~m}$ from one another to avoid resampling the same genetic individual. One leaf was taken at the fifth node from the base of each plant or at the next higher node with a leaf if a leaf was not present at the fifth node. Leaves that had evidence of herbivory were not sampled because of the difficulty in estimating intact leaf size. A total of 362 plants from 20 populations were sampled in the field, and 130 plants from 30 populations representing all five regions were sampled in the greenhouse. Greenhouse plants that were sampled included a subset of plants that were used for fitness estimates in 2001 (see "Fitness Estimates") and plants from seeds that had been col- lected in previous years. Each leaf was secured to a note card with clear tape and labeled with the population identity and a unique number. Leaves were dried and stored in a plant press until they could be photographed.

Digital images of the leaves included a ruler for scale. Images were captured using a monochromatic video camera attached to a computer with a frame grabber and Vidcam 32 software. Images were analyzed using the automated object recognition and area estimation procedures available in Optimus (version 5.2). Two measurements were taken from each leaf. First, the area of the whole leaf $(L)$ was estimated, and then the area of one-half of the leaf $\left(M_{1}\right)$ was taken by drawing the region to be analyzed along the midrib so that it encompassed only one side of the leaf. The area of the second leaf half $\left(M_{2}\right)$ was estimated by subtracting $M_{1}$ from the total leaf area $\left(M_{2}=L-M_{1}\right)$, and the level of (raw or signed) asymmetry was calculated as the difference between these two values $\left(A=\ln M_{2}-\ln M_{1}\right)$. The natural logarithm of each area measurement was used to produce a scale-free and less size-dependent measure of FA (Palmer and Strobeck 2003). In some instances, the midline of viridis leaves needed to be highlighted with a pen before the leaf was photographed, and a few of these leaves had to be excluded from the study because they were too dark or thin for Optimus to measure their areas accurately. Because $M_{1}$ and $M_{2}$ do not refer to particular sides, we did not attempt to assess levels of directional asymmetry, which would be characterized by a larger mean value for the left or right side of leaves.

FA was estimated as the absolute value (unsigned value) of the difference between the two leaf halves for each plant sampled $\left(A_{\mathrm{A}}=\left|\ln M_{1}-\ln M_{2}\right|\right.$; Palmer and Strobeck 2003). Although there was a significant relationship between this measure of asymmetry and the total leaf area $(P<0.001)$, this relationship was not isometric (i.e., the intercept was significantly different from zero; $P<0.001)$; therefore, scaling FA by leaf size (Palmer and Strobeck 1986) is not appropriate because of problems associated with the statistical properties of ratios (Møller and Swaddle 1997). As an alternative, we accounted for the effects of leaf size on $A_{\mathrm{A}}$ by including the total leaf area as a covariate in our ANOVA models (Swaddle et al. 1994).

\section{Fitness Estimates}

In summer 2000, we collected seeds from three of the five regions sampled for asymmetry: allopatric Piriqueta populations of the $\mathrm{C}$ (region 1,14 populations) and $\mathrm{V}$ (region 5, 10 populations) morphotypes and advanced-generation hybrid derivative genotypes in the center of the hybrid zone $(\mathrm{H}$; region 3, 11 populations; fig. 1). Seeds were sown in the greenhouse and grown to flowering. A subset of these plants were sampled for leaf asymmetry estimates (see "Leaf Collections and Measurements"). Between three and five cuttings were taken from each of 20-25 genotypes from each region and rooted in the greenhouse. Each cutting consisted of two nodes and a single leaf, and cuttings were treated with a fungicide/rooting hormone mixture before being planted into peat pellets. After $3 \mathrm{wk}$, cuttings were moved outside the greenhouse to acclimate for $1 \mathrm{wk}$ before being transplanted into common gardens in the field. 
Cuttings were planted in common gardens on the property of Archbold Biological Station (Venus, Fla.), which is located at the southern edge of the Piriqueta hybrid zone. The transplant garden was situated in an area that matched typical natural habitat for this species (sparsely vegetated open areas), in yellow sandhill, turkey oak scrub (Red Hill), which was similar to Piriqueta sites found in central and northern Florida. The garden site was separated from naturally occurring Piriqueta populations by several kilometers. Cuttings from all three regions were randomly distributed among 60 blocks of three plants each (180 plants total), with individual plants spaced $20 \mathrm{~cm}$ apart within each block. Each block contained one representative of a randomly selected genotype from each of the three regions $(\mathrm{C}, \mathrm{H}$, and $\mathrm{V})$, so that the cuttings from each individual genotype were spread across several blocks to allow for the statistical control on local environmental effects.

Cuttings were planted at the beginning of July 2001 and were monitored for three seasons in 2001, 2002, and 2003. At the time cuttings were transplanted to the field, most had new shoots, and initial size measurements were taken. Cuttings were measured for stem height and the number of leaves, buds, flowers, and fruits present at each census. In 2001, measurements were made every $2 \mathrm{wk}$ for the first 2 mo (through the end of August) with a final measurement after a 4-wk interval toward the end of September. In 2002, plants were measured three times (May, August, and September), and in 2003, plants were measured four times (May, July, August, and October). Plants begin to go dormant in November of each year and reemerge in the spring (M. B. Cruzan, personal observations); therefore, no measurements were made in the fall or winter months.

\section{Data Analysis}

Asymmetry data were first analyzed to determine whether the observed variation in asymmetry among individuals within populations was greater than the level of error, to ensure that our estimates of FA were not simply an artifact of the methods employed (Møller and Swaddle 1997). Errors for measurements on leaves from all five regions were assessed by repeating the area estimates 20 times for a single photographed leaf from one population in each region. The level of variance for repeated estimates of FA $\left(A_{\mathrm{A}}\right)$ was compared with the variance in FA for population samples from the same region using a Levine's test (Palmer and Strobeck 1986, 2003) implemented with the SUMMARY and GLM procedures of SAS (SAS Institute 1999). This method uses ANOVA to compare the magnitude of individual measurement deviations from their mean values to confirm that observed levels of FA among individuals were greater than measurement error.

Distributions of FA were examined for departures from normality to detect antisymmetry and possible selection against asymmetry. We tested signed asymmetry $\left(A_{\mathrm{A}}\right)$ for significantly higher or lower levels of kurtosis than expected for a normally distributed variable using the Shapiro-Wilk test (SAS Institute 1999). If the distribution of the signed values for FA differs from normal, it indicates either antisymmetry (indicated by high kurtosis [platykurtic distributions]) or evi- dence for strong canalizing selection (indicated by low kurtosis [leptokurtic distributions]; Palmer 1996).

We examined both the mean $\left(A_{\mathrm{A}}\right)$ and variance $\left(D A_{\mathrm{A}}\right)$ in FA in allopatric and hybrid populations to assess the effects of time since initial hybridization on the average level of random deviations from symmetry and variation among hybrid genotypes in their individual expression of developmental homeostasis. Differences in FA among regions (two allopatric and three hybrid zones) and environments (greenhouse vs. field) were tested using unsigned values $\left(A_{\mathrm{A}}\right)$. The withinpopulation variance in asymmetry was estimated as absolute deviations from the mean unsigned FA $\left(D A_{\mathrm{A}}=|\bar{A}-A|\right.$, where $\bar{A}$ is the mean asymmetry for the population). We expected that the mean absolute asymmetry $\left(A_{\mathrm{A}}\right)$ in hybrid populations would provide an indication of the average level of genetic stress, while the variance in asymmetry among individuals $\left(D A_{\mathrm{A}}\right)$ would provide an assessment of variation in the level of stress due to differences among individual recombinant genotypes (Palmer and Strobeck 1986). These values were used as response variables in tests for differences among regions and for differences due to greenhouse or field origin (environment), with ANOVA models that included population as a nested factor (within region) and total leaf area as a covariate, using the GLM procedure of SAS (SAS Institute 1999). We further tested for differences between hybrid and allopatric populations and for differences between "younger" (region 2) and "older" (region 3) hybrid populations, using contrast statements of the GLM procedure of SAS (SAS Institute 1999).

We estimated aboveground biomass of cuttings as the product of plant height and leaf number and used this metric as a surrogate for vegetative fitness. This estimate of plant size is independent of phylogenetically associated morphological traits (i.e., parental genotypes do not differ for this value under greenhouse conditions; M. B. Cruzan, unpublished data). Our estimate of aboveground biomass provided an adequate approximation of fitness that reflects the reproductive value of individuals (e.g., plant size should be a good predictor of future survival and reproduction; Caswell 1989), and plant size explains a significant proportion of variation in overwinter survival and future reproduction in Piriqueta (Cruzan and Rhode 2004; M. B. Cruzan, unpublished data).

We used SAS GLM (SAS Institute 1999) repeated measures and univariate ANOVA analyses to assess the effects of type (parental or hybrid) and population origin on the vegetative fitness of cuttings over the field in the three field seasons. Growth in the first season was analyzed with repeated measures, but it was not possible to use a repeated-measures model for the analysis of growth over three seasons because individual plants were not always present aboveground in the second and third years. In these analyses, block location was used as a random factor to remove spatial effects, population (treated as random) was nested within type $(\mathrm{C}, \mathrm{H}$, or $\mathrm{V})$, and initial size was entered as a covariate for the firstseason analysis. In all cases, the denominator mean square (MS) for the effect of type was calculated by SAS as a conglomerate of the among-population MS and the error MS using the "random" statement with the "test" option (SAS Institute 1999). Regression analyses (SAS REG; SAS Institute 1999) were used to examine the predictive value of the level 
of leaf FA for fitness using both population averages $\left(D A_{\mathrm{A}}\right.$ and $A_{\mathrm{A}}$ ) and individual genotypes (with greenhouse estimates of $A_{\mathrm{A}}$ ).

By the end of the third growing season, only 65 of the original 180 plants had produced reproductive structures at any time over the three seasons of monitoring, and only 55 were still alive (i.e., they were present in at least one of the last three censuses). We analyzed reproductive status and survival data with categorical response models, using the CATMOD procedure of SAS (maximum likelihood with other options set at their default values; SAS Institute 1999). In these models, initial plant size was a continuous (direct) variable, and block location within the garden and type $(\mathrm{C}, \mathrm{H}$, or $\mathrm{V})$ were categorical variables. Response variables were survival to the end of the third season (classified as dead or alive on the basis of their presence in the last three censuses) and reproductive or vegetative, on the basis of whether reproductive structures (bud, flower, or fruit) had been recorded during any of the 12 censuses over three seasons.

\section{Results}

Both the total area of Piriqueta leaves and their shapes, as measured by the width-to-length ratio, differed among the five allopatric and hybrid zone regions (fig. 2). The relative width (W/L ratio: $\left.F_{4,460}=263.75, P<0.0001\right)$ and total area of leaves $\left(F_{4,460}=49.94, P<0.0001\right)$ tended to decrease from north to south along the Florida peninsula. The only exception to this trend was in the center of the hybrid zone (region 3), where leaves were slightly smaller and narrower than in the southern hybrid zone (region 4; fig. 2). The mean leaf widths for each region were significantly different from each other for all comparisons. Total leaf area also tended to decrease from north to south, but the means for regions 1 and 2 and for regions 3 and 4 were not significantly different from each other (fig. 2).

Effects of environmental variation on FA were weak, but leaf size had a stronger influence on FA estimates. Regression

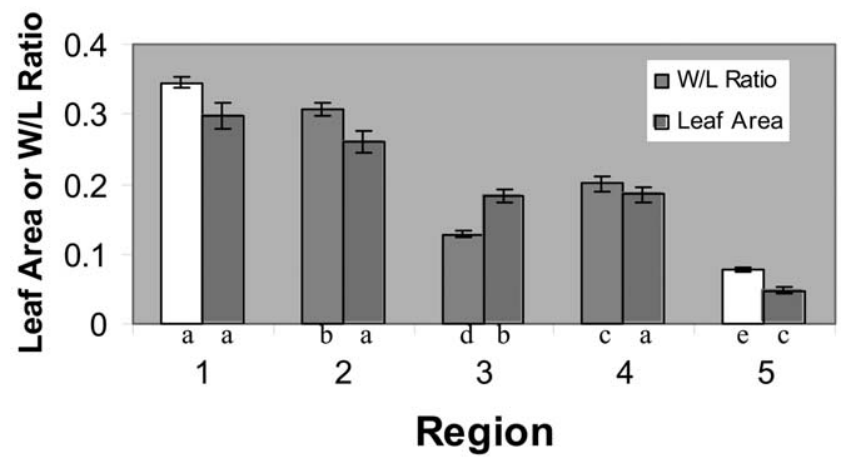

Fig. 2 Total area of leaves and leaf width-to-length ratio for parental (open bars) and hybrid (gray bars) genotypes in the Piriqueta caroliniana complex. The five regions are defined in fig. 1. Error bars represent standard errors. Bars within the same group (area or ratio) sharing the same lowercase letters are not significantly different from each other on the basis of Tukey's multiple-range tests.

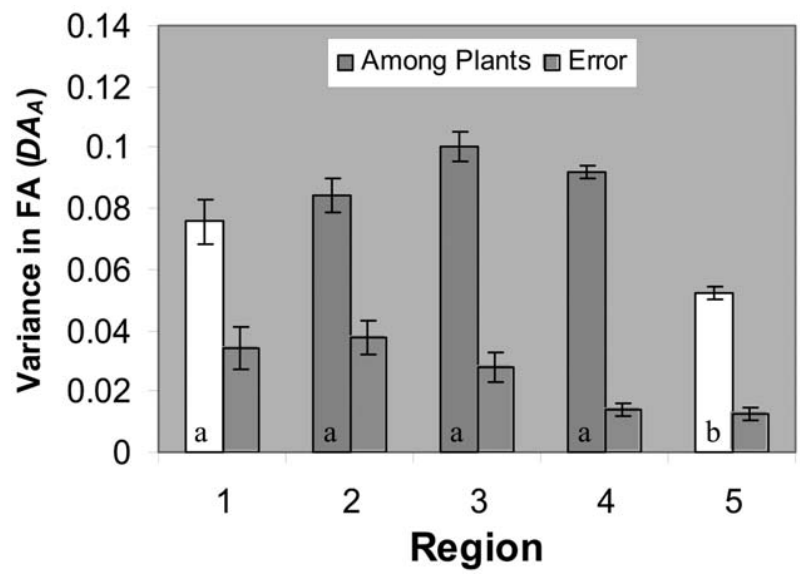

Fig. 3 Levels of variance in fluctuating asymmetry (unsigned FA) among plants and levels of measurement error within allopatric (open bars) and hybrid zone (gray bars) regions for the Piriqueta caroliniana hybrid zone in central Florida. Bars sharing the same lowercase letters are not significantly different from each other on the basis of Tukey's multiple-range test. Measurement errors were determined by remeasuring a single leaf from each zone 20 times. In all cases, variation in the single-leaf measurement errors were significantly lower than the among-plant variation. Regions are defined in fig. 1. Error bars represent standard errors.

models indicate that unsigned log-transformed estimates of asymmetry $\left(A_{\mathrm{A}}\right)$ were positively correlated with total leaf area $(t=6.27, P<0.0001)$, and this relationship holds when the effects of region, environment, and population were held constant $\left(F_{1,460}=15.80, P<0.0001\right)$. Environmental variation (greenhouse vs. field) had only small influences on absolute asymmetry $\left(F_{1,460}=1.25, P>0.26\right)$ and the variance in asymmetry $\left(F_{1,460}=0.0, P>0.95\right)$. We controlled for the effects of both leaf size and environment on estimates of FA by including the former as a covariate and the latter as a fixed factor in all of our ANOVA models.

We assessed levels of error for our estimates of FA in all five regions to insure that the observed variation among plants was from morphological differences among leaves rather than measurement error. In all cases, the variance of repeated measures of FA for individual leaves within each region was significantly lower than the levels of variation found among leaves in field populations $\left(D A_{\mathrm{A}}: P<0.001\right.$ in all regions; fig. 3). The distribution of signed log-transformed values of FA $(A)$ was strongly leptokurtic (kurtosis $=4.02$, Shapiro-Wilk's $W=0.91, P<0.0001$ ), indicating a lower variance in values than expected for a normal distribution.

Mean levels of and variance in FA did not vary substantially among regions but tended to be somewhat higher for plants from the hybrid zone. There were marginally significant differences in the mean $\left(F_{4,460}=2.36, P=0.0581\right)$ and variance $\left(F_{4,460}=5.50, P=0.0766\right)$ for estimates of absolute FA, but in both cases, only leaves from V populations had lower values based on Tukey's multiple-range tests (figs. $3,4)$. When all allopatric populations are compared with all hybrid populations using a priori contrasts, the FA mean $\left(A_{\mathrm{A}}: \quad F_{1,460}=12.40, \quad P=0.0005\right)$ and variance $\left(D A_{\mathrm{A}}\right.$ : 


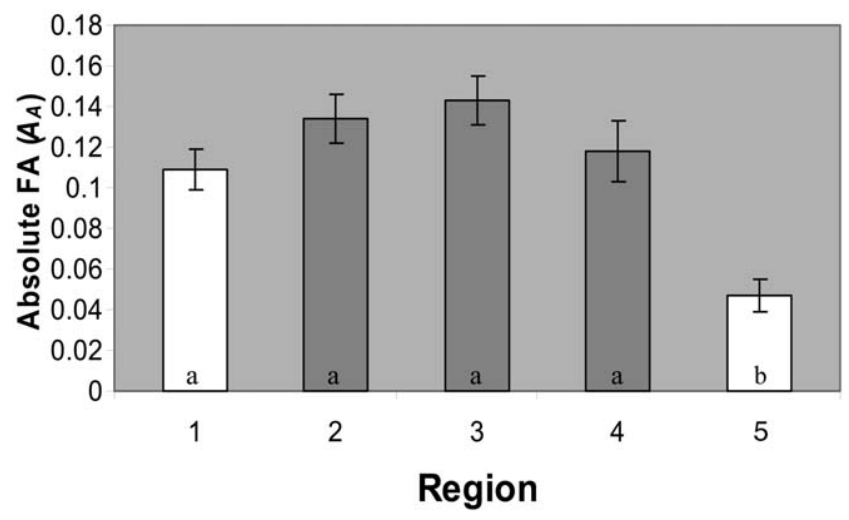

Fig. 4 Mean levels of fluctuating asymmetry (unsigned FA) within allopatric (open bars) and hybrid zone (gray bars) regions for the Piriqueta caroliniana hybrid zone in central Florida. Bars sharing the same lowercase letters are not significantly different from each other on the basis of Tukey's multiple-range test. Regions are defined in fig. 1. Error bars represent standard errors.

$\left.F_{1,460}=10.92, P=0.0010\right)$ is significantly greater for hybrids. Within the hybrid zone, levels of FA $\left(A_{\mathrm{A}}: F_{1,460}=0.14\right.$, $P=0.7099)$ and variance $\left(D A_{\mathrm{A}}: F_{1,460}=0.21, P=0.6427\right)$ did not differ between the younger and older hybrid populations. The higher estimates for $A_{\mathrm{A}}$ and $D A_{\mathrm{A}}$ for hybrid plants were similar both in the field and in the greenhouse and remained consistent when total leaf area was held constant.

Levels of vegetative fitness were similar among the three parental morphotypes over the three field seasons. There were significant differences among types $(\mathrm{C}, \mathrm{H}$, and $\mathrm{V})$ at the fourth $\left(F_{1,460}=4.03, P=0.0335\right)$, fifth $\left(F_{1,460}=4.08\right.$, $P=0.0311)$, and eighth $\left(F_{1,460}=3.92, P=0.0360\right)$ censuses and marginal differences at the sixth $\left(F_{1,460}=3.20\right.$, $P=0.0706)$ and seventh $\left(F_{1,460}=2.84, P=0.0702\right)$ censuses (fig. 5). However, the size order switched between censuses, with $\mathrm{C}$ and $\mathrm{V}$ genotypes being the largest at different time periods, and there was no consistent difference among types across the first field season (repeated-measures $\left.F_{1,460}=1.50, P=0.2354\right)$. The proportion of plants that had reproduced by the end of the third season was highest for $\mathrm{C}(0.43)$ and $\mathrm{H}(0.40)$ genotypes and lowest for plants from south Florida $(\mathrm{V}, 0.25)$, but these differences were not significant $\left(\chi^{2}=2.29, P=0.3177\right)$. There was also no difference in the number of reproductive structures (buds, flowers, and fruits) produced by the three different types $\left(F_{1,460}=0.39, P=0.6770\right)$ or the total number of fruits produced $\left(F_{1,460}=0.26, P=0.7698\right)$ by the end of the third season. Survival to the end of the third season was also very similar among types, with $28.3 \%, 31.7 \%$, and $31.7 \%$ survival for $\mathrm{C}, \mathrm{H}$, and $\mathrm{V}$, respectively $\left(\chi^{2}=0.28, P=0.8696\right)$. In the above analyses, initial size was a good predictor of growth in the first season $\left(F_{1,460}=61.59, P<0.0001\right)$, and size at the end of the first season was a good predictor of the proportion of plants reproducing $\left(\chi^{2}=4.56, P=0.0327\right)$, the total number of fruits produced $\left(F_{1,460}=4.32\right.$, $P=0.0422)$, and the proportion of plants alive at the end of the third season $\left(\chi^{2}=4.56, P=0.0327\right)$. For all of these analyses, there were generally only minor levels of variation that were attributable to population origin or position of plants (block) within the common garden $(P>0.05$ in all cases).

Regression analyses indicate that the level of leaf FA was a poor predictor of fitness (aboveground biomass) for both the population averages (for $A_{\mathrm{A}}$ : slope $=-1.51, P>0.30$ for 17 populations; for $D A_{\mathrm{A}}$ : slope $=-0.095, P>0.33$ for 17 populations) and the individual genotype estimates of fitness and FA ( $A_{\mathrm{A}}$ : slope $=-0.02, P>0.61$ for 39 genotypes).

\section{Discussion}

Overall levels of FA for leaf morphology were marginally greater for plants of hybrid origin than for plants in allopatric regions of these morphotypes in the Piriqueta caroliniana complex. The higher level of developmental instability in hybrids is, on the one hand, expected and is consistent with previous studies in a broad range of plants and animals (Graham and Felley 1985; Leary et al. 1985; but see Lamb et al. 1990; Alibert et al. 1994; Dosselman et al. 1998; Wilsey et al. 1998; Hochwender and Fritz 1999; Siikamaki 1999). On the other hand, results from these previous studies would also predict that departures from bilateral symmetry would be indicative of reduced growth and fecundity (Van Valen 1962; Møller and Swaddle 1997; Møller and Shykoff 1999), presumably as a side effect of genetic incompatibilities manifested as a consequence of hybrid breakdown (Graham 1992). However, in this particular study, it appears that these advanced-generation Piriqueta hybrids are of equal fitness to the genotypes of the parental morphotypes from allopatric regions. Hence, the expression of increased developmental

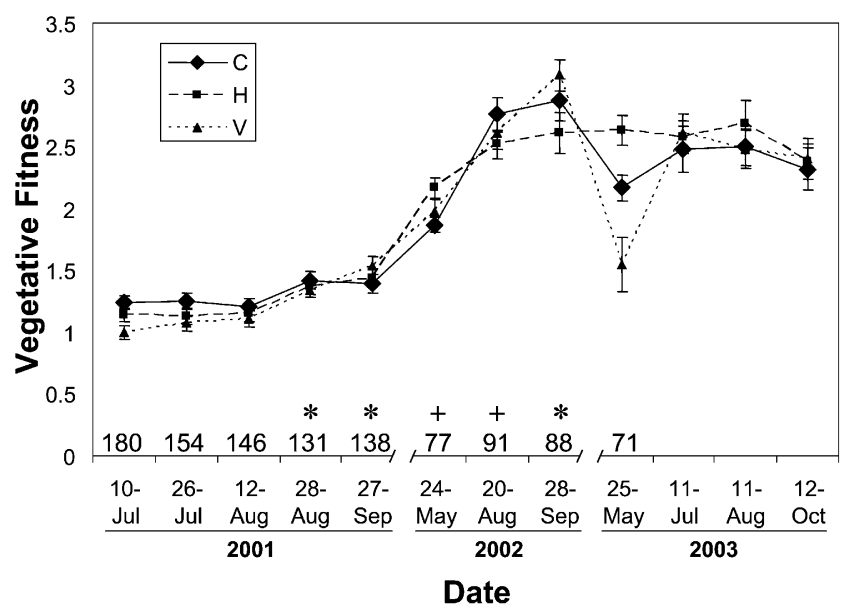

Fig. 5 Three seasons of growth of cuttings of Piriqueta caroliniana plants (types) from region 1 (C, allopatric caroliniana), region $3(H$, central hybrid zone), and region 5 ( $V$, allopatric viridis) grown in a common garden under field conditions. Each hybrid or parental plant was replicated with three to five cuttings that were randomly assigned to blocks in a complete block design. Numbers of surviving individuals at each census are given across the bottom, and significant (asterisk for $P<0.05$ ) or marginal (plus sign for $P<0.10$ ) differences among types are indicated for each census. 
instability in Piriqueta hybrids appears to have a more complex basis and may be somewhat inconsequential as an index of overall fitness.

Total leaf area and leaf width were greatest for the allopatric $\mathrm{C}$ populations, intermediate for hybrid populations, and substantially lower in the southern allopatric $\mathrm{V}$ region. Although estimated levels of FA might have been affected by the large variation in leaf shape encountered in this study, it did not appear to introduce any systematic error into the results. For example, leaves from the northern $\mathrm{C}$ populations had intermediate levels of asymmetry in spite of the fact that they were the largest and would be expected to have the greatest level of FA if it were simply a function of leaf size. It is also important to note that error measurements were relatively low in the $\mathrm{V}$ populations, even though these were the most difficult to measure. For all five regions, the amongindividual variation in leaf asymmetry was substantially greater than our error estimates, indicating that the patterns of FA we detected were not simply an artifact of the methods employed.

Estimated levels of fitness did not differ substantially among the parental and hybrid derivative genotypes used in this study. The results of this three-season analysis of growth, reproduction, and survival of these plants indicate that the advanced-generation hybrid derivative plants $(\mathrm{H}$ : region 3 ) do not have lower fitness than either of the allopatric parental morphotypes (C and V: regions 1 and 5, respectively). Plants from all three regions had nearly equal rates of growth, survival, and reproduction over the three seasons they were monitored. Similar patterns of growth performance among parental and hybrid derivative genotypes have been found over three different transplant gardens started from seedlings and cuttings that have been followed for up to 3 yr (Cruzan and Rhode 2004; M. B. Cruzan and J. M. Rhode, unpublished data). These results, combined with the analyses of FA reported in this article, indicate that higher levels of asymmetry in leaves is not a good indicator of fitness for plants in this hybrid complex.

From many standpoints, leaf asymmetry in plants could be a nearly ideal indicator of developmental instability. First, the presence of a midrib in many species renders area estimates for the opposing sides of these organs relatively unambiguous. Furthermore, unlike many structures in plant and animal species, leaves do not have to be perfectly balanced to avoid impeding locomotion or reproduction; therefore, one would expect that canalizing selection on these structures would be relatively weak. With lax selection on leaf symmetry, we might expect that departures from symmetry could be rather large without severely compromising the efficiency of the organ. A lack of severe fitness consequences for departures from perfect symmetry would allow for relatively large FA in leaves and would perhaps make leaves more sensitive to low levels of environmental or genetic stress than other organs that might be under stronger canalizing selection. Although the strongly leptokurtic distributions for signed measures of FA observed in this study on Piriqueta and others have been interpreted as evidence for strong selection for symmetrical structures (Palmer and Strobeck 1986), this may be an erroneous interpretation. Given that plants from the hybrid Piriqueta populations that had the highest levels of FA also had the highest rates of growth and reproduction under field conditions, it seems more likely that the strongly leptokurtic distributions found in this study are an artifact of developmental processes.

Previous investigations have mostly found large increases in levels of FA in hybrids relative to their parental progenitors (Manley and Ledig 1979; Graham and Felley 1985; Leary et al. 1985; Graham 1992; Clark 1993; Wilsey et al. 1998), and estimated levels of FA have been used as an indication of low hybrid fitness (Lu and Bernatchez 1999; Siikamaki 1999). However, it has been suggested that FA is not a good index of genetic stress (Kark et al. 2001), a conclusion that is also support by this study on Piriqueta hybrids. For example, it is possible that selection on levels of FA in leaves is relatively weak and that the observed increases in asymmetry in advanced-generation recombinant hybrids are due to weak genetic incompatibilities that have not yet been purged from these populations. In this case, we would expect that the observed increases in FA would be due to epistasis or dominance among genetic elements for which the fitness consequences were small or absent. These weakly incompatible alleles may have become fixed in hybrid populations as a consequence of drift in small populations.

Other factors that are unrelated to the hybrid origin of the central Florida populations may have influenced their observed elevated levels of FA. For example, it is possible that selection in central Florida is less severe, so that less symmetrical individuals survive in these habitats. It has been suggested that with weaker selection young plants with high levels of developmental stability may have better survival (Lamb et al. 1990; Lu and Bernatchez 1999), which may increase the mean average level of asymmetry for the population. However, note that we also observed higher levels in FA for hybrid plants grown under greenhouse conditions. Hence, there is no support for the hypotheses that the strength of the selection regime or the level of environmental stress were the causes of the observed increase in FA in these Piriqueta hybrids.

Overall, the increases in FA observed for Piriqueta of hybrid origin were relatively small. This may be the result of relatively recent divergence among the parental lineages (i.e., within the last million years; Maskas and Cruzan 2000), so that genetic differences between the two taxa are not great enough to manifest developmental instability in their hybrids (e.g., Hochwender and Fritz 1999). However, it is possible that there has been adequate time since the initial formation of this hybrid zone for the most asymmetrical genotypes to be eliminated. It is probable that the observed low levels of FA in these Piriqueta hybrids is from a combination of the recent divergence of the parental lineages and historical episodes of selection that purged these populations of the most severe genetic incompatibilities. However, full analysis of these hypotheses would require an examination of levels of asymmetry in early-generation and later-generation hybrids as well as parental genotypes.

This study of patterns of FA for plants with different histories of hybridization highlights a number of cautions for the use of FA as an indicator of genetic stress and fitness. First, it is an interesting observation that the advanced-generation hybrids used in this study have relatively high fitness in spite of 
their display of significantly elevated levels of FA. In this case, it could be that positive epistasis in these recombinant genomes outweighs the mildly deleterious genetic incompatibilities that lead to symptomatic effects of elevated leaf asymmetry. Second, it is possible that, while leaf asymmetry provides a highly sensitive measure of developmental instability, the underlying genetic causes of small departures from perfect symmetry may be inconsequential in terms of overall fitness. This may be particularly true in plants where organ symmetry is often not critical for efficient function. Continued studies of the causes and consequences of asymmetry in plants will continue to elucidate direct and indirect effects on the function of individual organs and on their growth, reproduction, and overall fitness.

\section{Acknowledgments}

This manuscript was significantly improved through comments on previous versions from J. M. Rhode. We also thank personnel and colleagues at the Archbold Biological Field Station for valuable discussion and technical assistance. S. M. Handy was supported for this work on a Research Experience for Undergraduates supplement to National Science Foundation grant DEB-0080437 to M. B. Cruzan.

\section{Literature Cited}

$\rightarrow$ Alibert P, S Renaud, B Dod, F Bonhomme, JC Auffray 1994 Fluctuating asymmetry in the Mus musculus hybrid zone: a heterotic effect in disrupted co-adapted genomes. Proc R Soc Lond B Biol Sci 258: 53-59.

$\rightarrow$ Andalo C, A Bazin, JA Shykoff 2000 Is there a genetic basis for fluctuating asymmetry and does it predict fitness in the plant Lotus corniculatus grown in different environments? Int J Plant Sci 161: 213-220.

Arbo MM 1995 Turneraceae. Pt 1. Piriqueta. New York Botanical Garden, New York.

Arnold ML 1997 Natural hybridization and evolution. Oxford University Press, New York.

$\rightarrow$ Arnold ML, SA Hodges 1995 Are natural hybrids fit or unfit relative to their parents? Trends Ecol Evol 10:67-71.

$\rightarrow$ Barton NH 2001 The role of hybridization in evolution. Mol Ecol 10:551-568.

Caswell H 1989 Matrix population models. Sinauer, Sunderland, Mass.

Clark GM 1993 The genetic basis of developmental stability. I. Relationships between stability, heterozygosity and genomic coadaptation. Genetics 89:15-23.

Cruzan MB, JM Rhode 2004 Experimental analysis of adaptive landscape topographies. Pages 61-69 in Q Cronk, ed. Plant adaptation. UBC, Vancouver, B.C.

Dosselman DJ, GB Schaalje, JW Sites 1998 An analysis of fluctuating asymmetry in a hybrid zone between two chromosome races of the Sceloporus grammicus complex (Squamata: Phrynosomatidae) in central Mexico. Herpetologica 54:434-447.

$\rightarrow$ Freeman DC, JH Graham, DW Byrd, ED McArthur, WA Turner 1995 Narrow hybrid zone between two species of big sagebrush, Artemisia tridentata (Asteraceae). III. Developmental instability. Am J Bot 82:1144-1152.

$\rightarrow$ Gavrilets S, MB Cruzan 1998 Neutral gene flow across single locus clines. Evolution 52:1277-1284.

Graham JH 1992 Genomic coadaptation and developmental stability in hybrid zones. Acta Zool Fenn 191:121-131.

Graham JH, JM Emlen, DC Freeman 2003 Nonlinear dynamics and developmental instability. Pages 35-50 in M Polak, ed. Developmental instability: causes and consequences. Oxford University Press, New York.

$\rightarrow$ Graham JH, JM Emlen, DC Freeman, LJ Leamy, JA Kieser 1998 Directional asymmetry and the measurement of developmental instability. Biol J Linn Soc 64:1-16.

$\rightarrow$ Graham JH, JD Felley 1985 Genomic coadaptation and developmental stability with introgressed populations of Enneacanthus glorosus and E. obesus (Pisces, Centarchidae). Evolution 39:104-114.

Graham JH, DC Freeman, JM Emlen 1993 Developmental stability: a sensitive indicator of populations under stress. Pages 136-158 in
WG Landis, JS Hughes, MA Lewis, eds. Environmental toxicology and risk assessment. American Society for Testing and Materials, Philadelphia.

$\rightarrow$ Graham JH, DC Freeman, ED McArthur 1995 Narrow hybrid zone between two subspecies of big sagebrush (Artemisia tridentata: Asteraceae). II. Selection gradients and hybrid fitness. Am J Bot 82: 709-716.

$\rightarrow$ Hochwender CG, RS Fritz 1999 Fluctuating asymmetry in a Salix hybrid system: the importance of genetic versus environmental causes. Evolution 53:408-416.

$\rightarrow$ Kark S, UN Safriel, C Tabarroni, E Randi 2001 Relationship between heterozygosity and asymmetry: a test across the distribution range. Heredity 86:119-127.

Lamb T, JM Novak, DL Mahoney 1990 Morphological asymmetry and interspecific hybridization: a case study using hylid frogs. Trends Ecol Evol 3:295-309.

$\rightarrow$ Leary RF, FW Allendorf 1989 Fluctuating asymmetry as an indicator of stress: implications for conservation biology. Trends Ecol Evol 4: 214-217.

$\rightarrow$ Leary RF, FW Allendorf, KL Knudsen 1985 Developmental instability and high meristic counts in interspecific hybrids of salmonid fishes. Evolution 39:1318-1326.

$\rightarrow$ Lexer C, ME Welch, O Raymond, LH Rieseberg 2003 The origin of ecological divergence in Helianthus paradoxus (Asteraceae): selection on transgressive characters in a novel hybrid habitat. Evolution 57:1989-2000.

$\rightarrow$ Lu GQ, L Bernatchez 1999 A study of fluctuating asymmetry in hybrids of dwarf and normal lake whitefish ecotypes (Coregonus clupeaformis) from different glacial races. Heredity 83:742-747.

$\rightarrow$ Manley SAM, FT Ledig 1979 Photosynthesis in black and red spruce and their hybrid derivatives: ecological isolation and hybrid adaptive inferiority. Can J Bot 57:305-314.

$\rightarrow$ Martin LJ, MB Cruzan 1999 Patterns of hybridization in the Piriqueta caroliniana complex in central Florida: evidence for an expanding hybrid zone. Evolution 53:1037-1049.

$\rightarrow$ Maskas SD, MB Cruzan 2000 Patterns of intraspecific diversification in the Piriqueta caroliniana complex in eastern North America and the Bahamas. Evolution 54:815-827.

$\rightarrow$ Mather K 1953 Genetical control of stability in development. Heredity 7:297-336.

$\rightarrow$ Møller AP, JA Shykoff 1999 Morphological developmental stability in plants: patterns and causes. Int J Plant Sci 160(suppl): S135-S146.

Møller AP, JP Swaddle 1997 Asymmetry, developmental stability, and evolution. Oxford University Press, New York. 291 pp.

Nijhout HF, G Davidowitz 2003 Developmental perspectives on phenotypic variation, canalization, and fluctuating asymmetry. 
Pages 3-13 in M Polak, ed. Developmental instability: causes and consequences. Oxford University Press, New York.

Ornduff R 1970 Relationships in the Piriqueta caroliniana: P. cistoides complex (Turneraceae). J Arnold Arbor Harv Univ 51:492-498.

$\rightarrow$ Palmer AR 1996 Waltzing with asymmetry: is fluctuating asymmetry a powerful new tool for biologists or just an alluring new dance step? BioScience 46:518-532.

$\rightarrow$ Palmer AR, C Strobeck 1986 Fluctuating asymmetry: measurement, analysis, and pattern. Annu Rev Ecol Syst 17:391-421.

2003 Fluctuating asymmetry analyses revisited. Pages 279-319 in M Polak, ed. Developmental instability: causes and consequences. Oxford University Press, New York.

$\rightarrow$ Parsons PA 1990 Fluctuating asymmetry: an epigenetic measure of stress. Biol Rev 65:131-145.

SAS Institute 1999 SAS/STAT user's guide, version 6. 4th ed. SAS Institute, Cary, N.C.

$\rightarrow$ Siikamaki P 1999 Developmental instability in hybrids between Lychnis viscaria and Lychnis alpina (Caryophyllaceae). Am J Bot 86:1683-1686.
Swaddle JP, MS Witter, IC Cuthill 1994 The analysis of fluctuating asymmetry. Anim Behav 48:986-989.

Thoday JM 1955 Balance, heterozygosity, developmental stability. Cold Spring Harbor Symp Quant Biol 20:318-326.

Tracy M, DC Freeman, JJ Duda, KJ Miglia, JH Graham, RA Hough 2003 Developmental instability: an appropriate indicator of plant fitness components? Pages 196-212 in M Polak, ed. Developmental instability: causes and consequences. Oxford University Press, New York.

$\rightarrow$ Van Valen LM 1962 A study of fluctuating asymmetry. Evolution 16: $125-142$.

Waddington $\mathrm{CH} 1957$ The strategy of the genes. Allen \& Unwin, London.

$\rightarrow$ Wang J, MB Cruzan 1998 Interspecific mating in the Piriqueta caroliniana (Turneraceae) complex: effects of pollen load size and composition. Am J Bot 85:1172-1179.

$\rightarrow$ Wilsey BJ, E Haukioja, J Koricheva, M Sulkinoja 1998 Leaf fluctuating asymmetry increases with hybridization and elevation in tree-line birches. Ecology 79:2092-2099. 